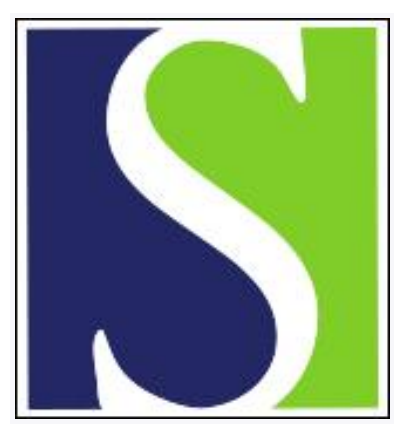

Scand J Work Environ Health 1992;18(5):273-277

https://doi.org/10.5271/sjweh.1577

Issue date: 01 Oct 1992

Problems and perspectives in the identification of new occupational carcinogens.

by Vineis $\mathrm{P}$, Blair $\mathrm{A}$

Affiliation: Unit of Cancer Epidemiology, Main Hospital, Torino, Italy.

This article in PubMed: www.ncbi.nlm.nih.gov/pubmed/1439652

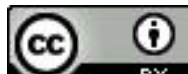




\title{
Problems and perspectives in the identification of new occupational carcinogens
}

\author{
by Paolo Vineis, MD, ${ }^{1}$ Aaron Blair, $\mathrm{PhD}^{2}$
}

\begin{abstract}
VINEIS P, BLAIR A. Problems and perspectives in the identification of new occupational carcinogens. Scand J Work Environ Health 1992;18:273-7. Occupational studies have played a major role in the identification of chemical carcinogens. There still remain, however, substances and occupations that deserve further evaluation. The more careful control of potentially hazardous exposures in most developed countries has necessitated a change in the conduct of epidemiologic investigations. The lowering of exposures and the lack of a simple correspondence between specific exposures and one or a few jobs underscores the need for careful reconstruction of historical exposures. The most successful reconstructions will include the integration of monitoring data, historical information on work histories and work practices, and use of biochemical markers.
\end{abstract}

Key terms: attributable risks, biomarkers, epidemiology, review.

Occupational studies have played a prominent role in the identification of environmental carcinogens. Over 25 agents and industrial processes evaluated in monographs 1-42 of the International Agency for Research on Cancer (IARC) are considered to be carcinogenic to humans (1). These agents and processes and the approximate dates of publication of the relevant evidence are presented in table 1 . It is interesting that all of the relevant studies were published before 1980 , and many of them before $1970(1,2)$. This time sequence suggests a decrease in the identification of occupational carcinogens. However, other explanations are possible.

One explanation might be that there has been a decrease in epidemiologic research on occupational exposures. There is no evidence, however, of such a tendency. To the contrary, 212 epidemiologic studies on occupational cancer were reported in 1977 in the IARC Directory of On-going Research in Cancer Epidemiology, while 442 were listed in 1989-1990, a twofold increase (3).

There may be a lag between initial discovery and the development of consensus among the scientific comThere are currently several chemicals with limited human evidence, including acrylonitrile, beryllium, acid mists, insecticide spraying, silica, formaldehyde, ethylene oxide, some organic solvents, and phenoxyacetic

1 Unit of Cancer Epidemiology, Main Hospital and University of Torino, Torino, Italy.

2 Occupational Studies Section, Environmental Epidemiology Branch, National Cancer Institute, Bethesda, Maryland, United States.

Reprint requests to: Dr P Vineis, Unit of Cancer Epidemiology, Main Hospital and University of Torino, via Santena 7, I-10126 Torino, Italy. herbicides. With additional evidence, these substances may eventually be included in the list of human carcinogens.

Epidemiologists tend to study well-known risks. Indeed, in the aforementioned IARC directory, the chemicals with the greatest number of on-going investigations include arsenic, asbestos, chromium, nick-

Table 1. Agents and industrial processes evaluated as carcinogenic to humans in IARC monographs $1-42$ and the approximate year of first demonstration of carcinogenicity. ${ }^{a}$

\begin{tabular}{lr}
\hline Agent or industrial process & \multicolumn{1}{c}{ Year } \\
\hline Aluminum production & 1979 \\
4-Aminobiphenyl & 1955 \\
Arsenic and arsenic compounds & 1947,1957 \\
Asbestos & 1935,1948 \\
Manufacture of auramine & 1954 \\
Benzene & 1930,1974 \\
Benzidine & 1949 \\
Bis(chloromethyl) ether (BCME) and & \\
chloromethyl methyl ether (CMME) & 1973 \\
Boot and shoe manufacturing & 1970 \\
Chromium compounds, hexavalent & 1953 \\
Coal gasification & 1931,1952 \\
Coal-tar pitches/coal tars & 1931,1976 \\
Coke production & 1920,1937 \\
Furniture and cabinet making & 1967 \\
Hematite mining (radon exposure) & 1956,1970 \\
Iron and steel founding & 1938,1975 \\
Isopropyl alcohol manufacturing & \\
(strong-acid process) & 1952,1966 \\
Manufacture of magenta & 1954 \\
Mineral oils (untreated and mildly treated) & 1937,1978 \\
Mustard gas & 1963 \\
2-Naphthylamine & 1954 \\
Nickel and nickel compounds & 1952 \\
Rubber industry & 1954 \\
Shale oils & 1922 \\
Soots & 1775,1937 \\
Talc containing asbestiform fibers & 1967 \\
Vinyl chloride & 1974,1976 \\
\hline
\end{tabular}

a Approximation is due to the fact that a single crucial investigation is identifiable for only a few chemicals. 
el, polycyclic aromatic hydrocarbons, and vinyl chloride, all of which have a long-standing demonstration of carcinogenicity (3). Others have noted this tendency and have suggested that new leads are not being followed-up as quickly as they should be (4). The increasing number of occupational studies between 1977 and 1990 suggests, however, that a focus on established carcinogens is likely to provide only a partial explanation of the decreasing discovery rate.

Since much of the occupational research takes place in developed countries, we believe the decreasing rate of discovery may reflect the increasing difficulty in uncovering occupational carcinogens. This difficulty could be due to changes which took place in the last few decades in occupational settings of the developed world. Exposure standards for recognized carcinogens have been tightened, and this change may have resulted in a general lowering of other exposures. Many hazardous activities have also been transferred to the Third World. For example, asbestos manufacturing has been transferred from the United States to Mexico, and from West Germany to Yugoslavia and Korea, and the production of benzidine has been transferred from Japan to several underdeveloped countries (5). This shift, and the generally improved work conditions in Western countries, would reduce exposures and make it more difficult to detect excesses of cancer incidence and mortality in epidemiologic investigations.

The change in the character of occupational settings in developed countries affects the sensitivity of traditional exposure assessment methods used in occupational epidemiology because exposures are less intense and because it is rare to see close correspondence between a specific exposure and one or a few job titles. For example, the carcinogenicity of mineral oils was discovered because of the use of such oils in "mulespinning" in the textile industry, the carcinogenicity of benzene because of its use in shoe factories, that of arsenic because of copper smelting, and so on. Many exposures under investigation today cannot be evaluated so simply. Exposures in today's workplaces, such as the aircraft industry or certain types of agricultural activities, cannot be described by identifying a few job titles which entail a limited number of chemical exposures. This complexity makes it difficult to link a specific job with a particular chemical exposure. For example, in agriculture more than one pesticide can be used on a crop during the year, several crops can be grown, and jobs are not specialized as to crop or chemical.

The modern occupational environment, with its more difficult to evaluate exposure situation, requires that occupational epidemiologists employ new approaches to generate leads. In the past, the generation of new hypotheses concerning occupational cancer occurred by (i) observation of series of cancer cases in specific occupations by clinicians or pathologists, such as in the example of vinyl chloride and liver angiosarcoma (6), (ii) description of case clusters (for example in a factory) by companies or the unions, such as in the example of bis(chloromethyl)ether (7), (iii) geographic correlations (ie, studies that related the concentration of specific industries to the frequency of cancer in given geographic areas (8), (iv) analysis of causes of death and jobs as reported on death certificates [this was the procedure which generated, for example, the association between electrical work and the risk of leukemia (9)], (v) studies based on the linkage of census data (related to occupations) and incidence or mortality statistics (10), and (vi) case-referent studies, in which the occupational histories of subjects affected by cancer (cases) are compared with those of healthy subjects (referents) (for examples concerning agriculture see reference 11 ).

These approaches, although limited because they are based primarily on job titles, worked reasonably well when exposures were high and the workplace was less complex. However, the limitation has become magnified in modern employment conditions of workers performing multiple tasks. For this reason some researchers have developed new and detailed exposureassessment procedures for both cohort $(12,13)$ and case-referent studies, for example, job-exposure matrices that link exposures to job titles $(14,15)$. The casereferent approach was developed to a high level in a project conducted in Montreal by Siemiatycki and his colleagues (16), in which very detailed occupational histories were collected from cancer cases and population referents. Occupational histories were subsequently evaluated by expert hygienists and chemists in order to assess exposure to chemical substances. One of the key aspects of this approach was the use of independent exposure assessments to validate the procedures. For example, the occupational histories of 18 welders were independently evaluated by three experts in welding and two chemists. On the average, 23 chemical exposures were attributed to each welder by these evaluators. The concordance between experts was $96 \%$, and the kappa index of interrater agreement was satisfactory (16).

Although the study by Siemiatycki and his colleagues was mainly devoted to the generation of new hypotheses, it dealt with a general problem of occupational studies (ie, the need to improve exposure assessment). Their effort went considerably beyond that typically expended on job-exposure matrices. It appears, however, to be worthwhile. A comparison of the Montreal approach with the typical job-exposure matrix type of effort indicated that the misclassification of exposures was reduced, the result being improved power to detect associations (17). The value of more quantitative exposure assessment procedures was also indicated in a review of occupational studies (18), which noted that detailed quantitative exposure estimates were more likely to show monotonic exposure-response gradients and large relative risks than studies that relied on duration of exposure. Although the results remain to be confirmed, the Montreal approach has provided sever- 
al new leads regarding cancer etiology, the relationship between non-Hodgkin's lymphomas and grain and cotton dust, prostate cancer and grain and paper dust, and gasoline exhausts and colorectal cancer (19-21). The background, methods, and results of the Montreal study have been recently published in a book (22).

\section{Use of biochemical markers}

The introduction of the use of biochemical markers into the occupational epidemiology of cancer has several different goals, including the same purpose as the aforementioned improvements in exposure assessment by experts (ie, to reduce the dilution of relative risks due to misclassification of exposure). The most promising markers would be those which reflect exposures specific to the time preceding cancer onset (to take induction time into account) and those which reflect interaction between chemical exposures and the biological target of the carcinogenic process. The first criterion is difficult to fulfill because of the turnover of easily accessible tissues for biomarker analyses in days or weeks, but not years, as would be required for cancer latency. One of the best candidates for further development and application to field studies are deoxyribonucleic acid (DNA) adducts, although the use is also limited by the short time elapsing between exposure and detection in most tissues. There is a small, but growing, number of examples of the measurement of adducts in the occupational setting. Table 2 shows the results of a study conducted among foundry workers in Finland. Both the proportion of subjects with benzopyrene-DNA adducts in their lymphocytes and the mean adduct level were clearly correlated with the level of exposure as measured by conventional methods (23); the adducts provide a consistent, monotonic trend.

Time is a limitation that is more of a problem for biochemical markers than for the expert assessment of exposure with the use of questionnaires. Cancer induction times are typically 20 years or more and biomarkers usually express exposures that occurred in recent weeks or months. New techniques may offer opportunities to overcome this limitation. For example, the mutation spectrum of $\mathrm{p} 53$ tumor suppressor gene among uranium miners showed a pattern of base substitutions that differed from those associated with tobacco (24). The technique may offer opportunities to identify markers specific for other occupational exposures.

On the other hand, information on occupational activities 20 or $\mathbf{3 0}$ years before interview can be obtained directly, although recall and expert assessment of exposure is relatively less accurate for events long past. Even though we believe that including biologic measures of exposure in epidemiologic studies is of value, it should not be taken for granted that a biomarker always performs better than a traditional tool, such as a questionnaire. For example, let us suppose we want to measure accurately the smoking habits of an occupational population in order to control for confounding. Urinary cotinine and nicotine levels may be more accurate than the use of a questionnaire; but how much, and at what cost? Is it worth collecting urine specimens, with the risk of conflicts and lack of trust on the part of the workers? If the positive predictive value of a questionnaire compared with that of a biochemical measure is 0.94 , what is the additional gain provided by cotinine-nicotine measurement? According to clinical epidemiology, our "rough" evaluation based on the questionnaire is the pretest probability that the individual smokes, and the cotinine-nicotine measurement represents the posttest probability. The contribution of the biomarker can be, therefore, estimated as the difference between the two probabilities. In this case the improvement is actually marginal. One property of this clinical reasoning is that the performance of a test is best in intermediate situations, but poorer in situations with very low a priori chances (say, pretest probabilities of $0.1-0.2$ or less) or almost certainty (probabilities of 0.9 or more). Use of biochemical measures to confirm exposure estimates based on other data should be encouraged, however. Disagreements between two approaches are also valuable. When inconsistencies occur, we may not be able to determine which exposure assessment is correct, but the situation indicates that exposure assessment is a problem.

\section{Need for occupational studies}

Although epidemiologic studies of occupational exposures may be more difficult today, they are needed to protect workers from preventable hazards, to identify new environmental hazards, to set public health priorities, and, when coupled with biochemical measures, to determine pathogenetic mechanisms. There are still many chemicals which are suspected human carcinogens but for which the human evidence is weak or lacking (1). Epidemiologic studies employing detailed exposure assessment procedures are needed to evaluate human risks posed by these substances and to identify new environmental hazards. Studies of occupational groups have played, and will continue to play, an important role in the identification of environmental carcinogens because exposures in the workplace

Table 2. Example of the use of biochemical markers in an occupational setting: polycyclic aromatic hydrocarbons-deoxyribonucleic acid adducts in foundry workers (23).

\begin{tabular}{lcc}
\hline Exposure group & $\begin{array}{c}\text { Percentage } \\
\text { positive }\end{array}$ & Mean adduct levela \\
\hline No exposure & 20 & 0.22 \\
Low exposure & 72 & 0.80 \\
Medium exposure & 100 & 2.1 \\
High exposure & 100 & 5.0 \\
\hline
\end{tabular}

a Mean number of adducts $/ 10^{7}$ nucleotides. 
are often heavier and of longer duration than those experienced by the general public.

It is important for planning purposes to know how many of the cancers that arise in a population are due to occupational exposures. Most estimates are around $5 \%(25,26)$. A systematic approach to estimating the burden of lung and bladder cancer attributable to occupation has been recently applied (27). In this exercise, all of the case-referent studies on occupation and bladder or lung cancer were reviewed. Only investigations which allowed for the control of confounding from tobacco smoking were considered, and standardized criteria were used to evaluate the literature published. The attributable risk for lung cancer ranged between 1 and $5 \%$ (in studies in which asbestos was the only or the main exposure considered) and $40 \%$ (in a study with a very high proportion of subjects exposed to ionizing radiation). For bladder cancer the estimates were between about 1 and $20 \%$. Considerable variability among geographic areas was noted, mainly as a consequence of variable proportions of exposed workers in the different populations studied. Within the United States estimates for lung cancer from five similarly designed studies ranged from $3 \%$ (Louisiana) to $17 \%$ (Pennsylvania) (28) (table 3). In this study, attributable risks were higher for blacks, a finding suggesting different levels of exposure to carcinogens within the same job. Overall, this systematic estimation of attributable risks indicates that a single figure at the national level may not be prudent, because of the large within-country variations. Although these estimates are not large, they are comparable with estimates for other environmental factors, except for smoking and diet $(25,29)$. Occupational exposures are, however, more easily preventable than life-style exposures. Prevention of occupational cancer requires a concerted international, national, and local effort. Regulations are particularly needed in countries, such as most of the Third World and Eastern Europe, where regulatory attention to occupational exposures has been weaker.

In summary, occupational studies have played a major role in the identification of chemical carcinogens. There still remain, however, substances and occupations that deserve further evaluation. The more careful control of potentially hazardous exposures in most developed countries has necessitated a change in the

Table 3. Proportion of exposed cases, relative risk, and proportion attributable to occupational exposure for occupations as. sociated with a high risk of lung cancer (included in a list of known lung carcinogens) in five states of the United States (28).

\begin{tabular}{lcccc}
\hline State & $\begin{array}{c}\text { Exposed } \\
\text { cases } \\
(\%)\end{array}$ & $\begin{array}{c}\text { Reiative } \\
\text { risk }\end{array}$ & $\begin{array}{c}\text { 95 confidence } \\
\text { interval }\end{array}$ & $\begin{array}{c}\text { Proportion } \\
\text { attributable }\end{array}$ \\
\hline Louisiana & 16 & 1.2 & $0.9-1.5$ & 3.0 \\
Virginia & 32 & 1.3 & $0.9-2.0$ & 10.0 \\
New Jersey & 26 & 1.4 & $1.1-1.8$ & 11.0 \\
Florida & 25 & 1.4 & $1.0-2.1$ & 10.0 \\
Pennsylvania & 43 & 1.4 & $0.9-2.1$ & 17.0 \\
\hline
\end{tabular}

adjusted for smoking status, age, and birth cohort. conduct of epidemiologic investigations. The lowering of exposures and the lack of a simple correspondence between specific exposures and one or a few jobs underscores the need for careful reconstruction of historical exposures. The most successful reconstructions will include the integration of monitoring data, historical information on work histories and work practices, and the use of biomarkers.

\section{Acknowledgments}

Part of this work was presented at the Meeting of the International Association of Cancer Registries (Hamburg, 1990) and at the XI Meeting of the European Association for Cancer Research (Genova, 1991). This work was partly supported by a grant from the "EEC - Europe Against Cancer Programme."

\section{References}

1. Vainio H, Hemminki K, Wilbourn J. Data on the carcinogenicity of chemicals in the IARC Monographs programme. Carcinogenesis 1985;6:1653-5.

2. International Agency for Research on Cancer (IARC). Monographs on the evaluation of carcinogenic risks of chemicals to humans; supplement 7. IARC, Lyon, 1987.

3. International Agency for Research on Cancer (IARC). Directory of on-going research in cancer epidemiology. Lyon: IARC, 1989. (IARC scientific publication; no 101).

4. Andersen A, Blair A, Fletcher A, Gardner MJ, Gérin $\mathrm{M}$, Halperin WH, et al. Workshop on priorities for epidemiologic studies on occupational cancer [report]. Scand J Work Environ Health 1987;13:74-5.

5. Simonato L. Occupational cancer risk in developing countries and priorities for epidemiological research. Presented at the International Symposium on Health and Environment in Developing Countries, Haikko, 1986.

6. Creech JL, Johnson MN. Angiosarcoma of liver in the manufacture of polyvinyl chloride. J Occup Med 1974; $16: 150-1$.

7. Thiess AM, Hey W, Zeller H. Zur Toxicologie von Dichlor-dimethylaether - Verdacht auf kanzerogene Wirkung auch beim Menschen. Zentralbl Arbeitsmed Arbeitssch 1973;27:97-102.

8. Hoover R, Fraumeni JF Jr. Cancer mortality in US counties with chemical industries. Environ Res 1975; 9:196-207.

9. Milham S Jr. Mortality from leukemia in workers exposed to electrical and magnetic fields. N Engl J Med 1982;307:249.

10. Lynge E, Thygesen L. Occupational cancer in Denmark: cancer incidence in the 1970 census population. Scand J Work Environ Health 1990;16 suppl 2:1-35.

11. Blair A, Hoar Zahm S. Cancer among farmers. Occupational Medicine: State of the Art Reviews 1991;6: 335-54.

12. Greife AL, Hornung RW, Stayner SL, Steenland KN. Development of a model for use in estimating exposure to ethylene oxide in a retrospective cohort mortality study. Scand J Work Environ Health 1988;14 suppl $1 ; 29-30$.

13. Stewart PA, Blair A, Cubit D, Bales RE, Kaplan SA, Ward J, et al. Estimating historical exposures to formaldehyde in a retrospective mortality study. Appl Ind Hyg 1986;1:34-41.

14. Pannett B, Coggon D, Acheson ED. A job-exposure ma- 
trix for use in population based studies in England and Wales. Br J Ind Med 1985;4:777-83.

15. Hoar SK, Morrison AS, Cole P, Silverman DT. An occupation and exposure linkage system for the study of occupational carcinogenesis. J Occup Med 1980;22: $722-6$.

16. Gerin M, Siemiatycki J, Kemper H, Begin D. Obtaining occupational exposure histories in epidemiologic case-controls studies. J Occup Med 1985;27:420-6.

17. Dewar R, Siemiatycki J, Gerin M. Loss of statistical power associated with the use of a job-exposure matrix in occupational case-control studies. Appl Occup Environ Health 1991;6:508-15.

18. Blair A, Stewart PA. Do quantitative exposure assessments improve risk estimates in occupational studies of cancer? Am J Ind Med. In press.

19. Siemiatycki J, Gérin $M$, Stewart $P$, Nadon L, Dewar $\mathrm{R}$, Richardson L. Associations between several sites of cancer and ten types of exhaust and combustion products: results from a case-referent study in Montreal. Scand J Work Environ Health 1988;14:79-90.

20. Siemiatycki J, Richardson L, Gerin M, Goldberg S, Dewar R, Desy M, et al. Associations between several sites of cancer and nine organic dusts: results from a hypothesis-generating case-control study in Montreal, 1979-1983. Am J Epidemiol 1986;123:235-49.

21. Siemiatycki J, Dewar R, Nadon L, Gérin M, Richardson L, Wacholder S. Associations between several sites of cancer and twelve petroleum-derived liquids: results from a case-referetn study in Montreal. Scand J Work
Environ Health 1987;13:493 - 504.

22. Siemyaticki J. Risk factors for cancer in the workplace. Boca Raton, FL: CRC Press, 1991.

23. Perera F, Hemminki K, Young TL, Brenner D, Kelly G, Santella RM. Detection of polycyclic aromatic hydrocarbon-DNA adducts in white blood cells of foundry workers. Cancer Res 1988;48:2288-91.

24. Vahakangas KH, Samet J, Metcalf RR, Walsh JA, Bennett WP, Lane DP, et al. Mutations of p53 and ras genes in radon-associated lung cancer from uranium miners. Lancet 1992;330:576-80.

25. Doll R, Peto R. The causes of cancer: quantitative estimates of avoidable risks of cancer in the United States. J Natl Cancer Inst 1981;66:1191-308.

26. Higginson J. Proportion of cancers due to occupation. Prev Med 1980;9:180-8.

27. Vineis $\mathbf{P}$, Simonato L. Proportion of cancers in males due to occupation: a systematic approach. Arch Environ Health 1991;46:6-15.

28. Vineis P, Thomas T, Hayes R, Blot WJ, Mason TJ, Williams Pickle L, et al. Proportion of lung cancers in males, due to occupation, in different areas of the USA. Int $\mathrm{J}$ Cancer 1988;42:851-6.

29. Tomatis L, ed. Cancer: causes, occurrence and control. Lyon: International Agency for Research on Cancer, 1990. (IARC scientific publications; no 100.)

Received for publication: 15 June 1992 